\title{
DE LA PANDEMIA DE LA COVID-19 A LA INFODEMIA: UNA PERSPECTIVA SISTÉMICA
}

\section{Javier Espinoza de los Monteros*}

No esculpir en tu mente alguna imagen inmutable: es decir, no de máximas o fórmulas

Sir Frederik Pollock

\begin{tabular}{l|l}
\hline RECEBIDO EM: & 13.5 .2021 \\
\hline APROVADO EM: & CONVIDADO \\
\hline
\end{tabular}

* Doutor em Direito pela Universidade do Salento, Itália. Coordinador del Centro para el Desarrollo Jurídico de la Facultad de Derecho de la Universidad Anáhuac México. E-mail: jespinozams@hotmail.com 
- RESUMEn: La pandemia demostró la falta de sentido en la sociedad moderna, mostrando la ausencia de certezas, teniendo en cuenta brechas semánticas como verdad, valores, derechos, fundamentos, propios de los sistemas sociales modernos para construir sentido, legitimidad. En medio de tanta información para afrontar la situación de emergencia, a través de los medios de comunicación, se ha producido simultáneamente más desinformación, circulación de noticias falsas (noticias falsas y erróneas), situación que pasó a conocerse como infodemia. Entonces, cuanto más sabes, más no sabes. El virus de la desinformación ayudó a que la enfermedad se extendiera a gran escala, multiplicando y extendiendo problemas como el discurso de odio, el racismo, la invención de la alteridad como amenaza, la polarización del debate político, la potencialización del contagio y, en general, la precariedad y la imposibilidad. de controlar de manera plausible el impacto de la pandemia y sus consecuencias. Por tanto, se analiza el papel de la ley y otros mecanismos, y sus límites, para contener este problema. PALABRAs clave: Pandemia. Infodemia. Sociedad moderna. Sistemas sociales.

\section{FROM THE COVID-19 PANDEMIC TO INFODEMIC: A SYSTEMIC PERSPECTIVE}

- ABStRAct: The pandemic demonstrated the lack of meaning in modern society, showing the absence of certainties, taking into account semantic gaps such as truth, values, rights, foundations, and current social systems to build meaning and legitimacy. Amidst so much information to face the emergency situation, through the media, there has been simultaneously more misinformation, circulation of false news (false and erroneous news), a situation that became known as infodemia. So the more you know, the more you don't know. The disinformation virus helped the disease spread on a large scale, multiplying and spreading problems such as hate speech, racism, the invention of alterity as a threat, the polarization of political debate, the potentization of contagion, and, in general, precariousness and the impossibility of plausibly controlling the impact of the pandemic and its consequences. Therefore, the role of law and other mechanisms, and their limits, to contain this problem is analyzed.

- Keywords: Pandemic. Infodemic. Modern society. Social systems. 


\section{DA PANDEMIA DO COVID 19 À INFODEMIA:} UMA PERSPECTIVA SISTEMICA

- Resumo: A pandemia demonstrou a falta de sentido da sociedade moderna, evidenciando a ausência de certezas, levando em consideração as lacunas semânticas como verdade, valores, direitos, fundamentos, particulares dos sistemas sociais modernos para construir sentido, legitimação. Em meio a tantas informações para enfrentar a situação de emergência, através dos meios de comunicação, tem havido simultaneamente mais desinformação, circulação de fake news (notícias falsas e errôneas), situação que ficou conhecida como infodemia. Assim, quanto mais você sabe, mais você não sabe. $\bigcirc$ vírus da desinformação auxiliou a disseminação da doença em larga escala, multiplicando e disseminando problemas como o discurso do ódio, o racismo, a invenção da alteridade como ameaça, a polarização do debate político, a potencialização do contágio e, em geral, a precariedade e a impossibilidade de controlar plausivelmente o impacto do a pandemia e suas consequências. Diante disso, analisa-se o papel do direito e de outros mecanismos, e seus limites, para conter esse problema.

- palavras-chave: Pandemia. Infodemia. Sociedade moderna. Sistemas sociais.

\section{Introducción}

Antes que nada agradezco la invitación al profesor Fernando Rister De Suosa Lima, y al profesor Celso Fernandez Campilongo. Celebro la organización de este ciclo de conferencias, que permite difundir y cultivar los estudios sobre la teoría sistémica; de aquí que hayamos podido realizar estas contribuciones, utilizando este enfoque y, sobre todo, poder dialogar y escuchar a otros colegas, enriquecernos de sus aportaciones y reflexiones. Esta teoría, sin duda, tiene un gran potencial descriptivo de la sociedad moderna, sobre cómo opera y lo que acontece en ella, en los particulares sistemas sociales; es indispensable, sobre todo en este momento, para la comprensión de lo que constituye nuestro horizonte de reflexión: Pandemia, medios, fake news, grandes temas, grandes universos cognitivos. 
La pandemia ha puesto de manifiesto la carencia de sentido de la sociedad moderna. La ausencia de certezas. Ante el vacío de estas semánticas tales como verdad, valores, derechos, fundamentos, los particulares sistemas sociales modernos tienen que construir significado, legitimación. Aquellas, por tanto, no son el orden del mundo, no pueden guiar, orientar el actuar de los sistemas. Asimismo, en su operar de estos sistemas sociales particulares, en específico en el derecho y en la política, se han practicado formas violentas de exclusión, una práctica legitimada en torno a los fundamentos, los cuales vienen utilizados como cáscaras protectoras de las decisiones. Ha sido, igualmente, un momento en el cual, en virtud de la situación indicada, ha constituido caldo de cultivo para los autoritarismos que, en el nombre del pueblo, del bien común, han actuado en forma devastadora y perjudicial.

Todo ello viene puesto de manifiesto en esta contribución, así como la paradoja de la seguridad de la información, como símbolo del progreso. En otras palabras, que entre más información para atender la situación de emergencia, a través de los medios de comunicación, se ha producido simultáneamente más desinformación, circulación de fake news (noticias falsas y erróneas). En efecto, entre más saber más no saber. Tal situación ha sido descrita como infodemia. Este virus de la desinformación, ciertamente, ha permitido la expansión de la enfermedad a una amplia escala. Y con ello se ha producido la multiplicación y difusión de discursos de odio, de racismo, la invención de la alteridad como amenaza, la polarización del debate político, la potencialización del contagio y, en general, la precariedad e incapacidad de controlar plausiblemente el impacto de la pandemia y sus consecuencias. Por último, se analiza cuál es el papel del derecho y de otros mecanismos, y sus límites, para la contención de este problema.

\section{Pandemia, orden social y certezas del actuar}

Ciertamente los problemas que ha generado la pandemia han sido objeto de reflexión desde la economía, la política, del derecho, de la educación, de la ciencia, de la moral, de la filosofía, de la sociología, etc. Una preocupación central: cómo se puede hacer frente a los problemas y cuáles son las soluciones, las respuestas posibles. ${ }^{1} \mathrm{El}$ panorama ha sido

1 Como se dice en la literatura "Los meses de emergencia sanitaria global se llenan de reflexiones desde la ética, la política, la sociología y sobre todo desde las tecnociencias. Visiones y prismas aportan con descripciones y posibles soluciones o por lo menos propuestas de acción. ESTÉVEZ ABAD, René Fernando. “¿Pandemia o pandemias?”, en Revista internacional de pensamiento político, I época, v. 15, 2020, p. 167. 
caracterizado por la impotencia pero también posibilidades de replanteamiento, de repensamiento. Ello en virtud de que vimos como se desquebrajan nuestros modelos cognitivos, su fragilidad, sus límites. De aquí no es extraño que surjan cuestionamientos:

El mundo ha vivido en estos meses un ajedrez de circunstancias mortales frente a las cuales la filosofía se ha visto abocada a probar su poder o su debilidad, su actualidad o caducidad. El drama radica en que ha debido hacerlo ante la amenaza inmisericorde de la muerte representada por un "enemigo invisible": el coronavirus. ${ }^{2}$

Aquí me parece que la teoría sistémica, tomando a distancia las otras descripciones de la modernidad, era consiente del modo del operar de la sociedad, de sus estrategias, del particular mondo, paradójico, en que se produce exclusión. Lo que para muchos la pandemia ha mostrado, ello era ya discutido desde hace tiempo, incluso a contracorriente, por la perspectiva sistémica. Aquí la competencia de la teoría.

Ahora bien, como ha observado Slavoj Žižek, el problema de la pandemia no solamente estriba en cuanto a poner de manifiesto lo esencial en nuestras vidas, estar enclaustrados, nuestras reales necesidades y nuestras relaciones afectivas ${ }^{3}$ sino también el problema del orden social.

Pensábamos que en virtud de nuestro progreso indefinido, podíamos controlar la situación, por lo que en todo caso y en sentido contrario, en efecto:

... el mundo occidental asistió absorto, incrédulo y tal vez algo despreocupado al desarrollo de los acontecimientos pues la historia reciente mostraba realidades en las que aparentemente habíamos pensado y nos habíamos preparado para situaciones catastróficas que nunca ocurrieron causadas por otros virus de similar origen.

Ya habían aparecido otros coronavirus, ya habíamos hecho experiencia y aún así ha puestos a los gobiernos y a los individuos de cabeza, se ha salido de control. Y es que sabíamos que era muy probable que sobrevinieran más de este tipo de virus. De hecho para Chomsky el origen del virus ha sido este capitalismo salvaje ${ }^{4}$, ya que

2 MADRID GUERRA BRAVO, Samuel. “Filosofía y pandemia”, en Sophia, Colección de Filosofía de la Educación, Universidad Politécnica Salesiana, n. 30, 2021, p. 246.

3 Cfr. ŽIŽEK, Slavoj, Pandemia. La covid 19 estremece al mundo. Traducción Damià Alou, Barcelona, Ed. Anagrama, 2020.

4 Cfr. CHOMSKY, Noam, "Pensadores ante la crisis”, disponible en: https://www.youtube.com/watch?v=C9tw09IzQdM 
no es rentable producir medicamentos huérfanos, esto es, que no tengan un mercado inmediato de consumo.

En la multiplicidad de problemas que giran en torno a la pandemia observamos que la reflexión se ha concentrado y preocupado respecto a qué nos podemos esperar entorno a: la seguridad de la información, la seguridad en el derecho, la seguridad en la política, la seguridad en la economía, la seguridad de la ciencia: certeza, verdad. En esta situación experimentamos inestabilidad, desazón, perturbación, desesperanza, desconcierto, falta de orientación, de un faro de luz.

Como se dice, se debería evitar la "ausencia de tierra firme" ${ }^{\text {. Y }}$ entonces ahora se tornó más visible, se puso a flote, se cuestionó: qué hay debajo de los fundamentos del mundo moderno. ${ }^{6}$

Por tanto, en esta pandemia, en muchos ámbitos, se adujo que nuestras certezas se habian disuelto. Ahora ya era un lugar común. Incluso se ha dicho que con esta pandemia se ha consumado la modernidad y se daba paso a una transmodernidad. ${ }^{7}$ Si bien nosotros hemos experimentado una constate incertidumbre, inseguridad, miedo, zozobra. No obstante, nos seguimos aferrando a nuestras certezas del mundo. Porque sentimos que es mejor apoyarnos en ellas que girar en torno al vacío, en torno a la nada. Por eso aquellas han sido tan persistentes. Buscamos, pues, un sentido, una orientación. De cualquier forma no se puede cerrar los ojos, no se puede soslayar que difícilmente nuestra confianza ciega en el progreso y en nuestras certezas ha quedado incólume.

De este modo, nos hemos mantenido entre la desilusión del presente y la esperanza hacia el futuro. Es decir, entre el desencanto de lo que estamos viviendo, de lo que estamos experimentando y la expectativa de que se pueda revertir la situación. Que la ciencia pueda hacer frente, rápidamente, a la contención y limitación de la propagación del virus, que las personas cuenten con una vacuna que permita prevenir el contagio, que los pueda inmunizar frente a éste. Que la política pueda realizar el bien común, el derecho pueda realizar la justicia, que exista una distribución más racional de la riqueza o,

5 LOSADA MAESTRE, Roberto. “Las Fake News en la crisis de la Sociedad digital”, en Más Poder Local, n. 41, abr. 2020 , p. 49.

6 DE GIORGI, Raffaele. Observación sociológica de la filosofía del derecho. Traducción del italiano Javier Espinoza de los Monteros, México, Ed. Derecho Global, 2018.

7 “... la pandemia se ha constituido en el verdadero fin de la modernidad eurocéntrica. Y, ojalá, en el verdadero fin de los imperialismos expansionistas y colonialistas. Se ha abierto una nueva etapa de la humanidad que algunos llaman transmodernidad.” MADRID GUERRA BRAVO, Samuel, op cit., p. 247. 
en su caso, se puedan garantizar los mínimos vitales, etc. Pero realísticamente: qué nos podemos esperar de nuestras certezas.

En esta sociedad, en la sociedad moderna, ciertamente no tenemos un sentido, una guía, una orientación. Como decía John Bury, el progreso no es otra cosa sino una ilusión de fin. ${ }^{8}$ Los sistemas sociales, en efecto, tienen que construir sentido: autolegitimarse. No persiguen fines sino funciones. Es así como operan autoreferencialmente, ellos construyen su orientación, lo que usan como realidad, como verdad, como certeza. La factualidad y la metafísica ${ }^{9}$ se presentan como asimetrías que pretenden romper la circularidad; solo que no la cancelan, la ocultan, las sustraen a la vista.

La precariedad del pensamiento occidental para dar respuesta a los problemas, para dar soluciones, para ofrecer certezas. La razón de los principios, la razón de la verdad, es la razón de un tiempo que se va consumiendo, de un tiempo cuyas narraciones que ahora ya, con esta situación, van perdiendo cada vez más legitimidad. A un ritmo acelerado.

Ahora bien, como decía Luhmann, el problema del orden social (moderno, naturalmente) no tiene una sola respuesta. ${ }^{10}$ Tienes múltiples respuestas, porque como esta sociedad se ha sustituido a un Dios que no se equivoca (orientación del mundo), siempre queda abierta la posibilidad, la binariedad, un segundo valor, un marco de opciones disponibles para la sedimentación de sentido. Ya no hay la orientación de un mundo ya dado, de un orden ya construido, predeterminado.

No obstante, se pone una cierta distancia, un apartamiento, porque queda el miedo de asumir la complejidad del mundo, de la sociedad. ${ }^{11}$ Mas constantemente hay construcción de mundo, se produce comunicación, se expande comunicación, se produce sentido.

En esta sociedad experimentamos formas más violentas de exclusión. Cada vez más brutales. Legitimadas, justificadas en el derecho y la política. Incluso fundamentadas en los valores. Pero este operar de la sociedad moderna, sus consecuencias, se han

8 BURY, John, La idea de progreso. Traducción. de Elías Díaz García, Madrid, Ed. Alianza, 2009, pp. 356-357.

9 LUHMANN, Niklas. "La observación sociológica del derecho". Traducción Héctor Fix-Fierro, en Crítica jurídica. Revista latinoamericana de Política, Filosofía y Derecho, n. 12, Universidad Nacional Autónoma de México-Instituto de Investigaciones Jurídicas, México, 1993, pp. 82-83.

10 LUHMANN, Niklas. ¿Cómo es posible el orden social?. Traducción Dario Rodríguez Manzilla y Javier Torres Nafarrete, México, Ed. Universidad Iberiamericana / Herder, 2011.

11 "Los sistemas sociales, en su interior, producen complejidad, excesos de posibilidades: esto es, una totalidad de acontecimientos posibles.” LUHMANN, Niklas. Ilustración sociológica y otros ensayos. Traducción H. A. Murena, Buenos Aires, Ed. SUR, 1973, p. 144. 
vuelto más visibles, se han acentuado, se han potencializado en esta pandemia. De ahí que se perciba más la sensación de inseguridad, de desasosiego. Vivimos las consecuencias de la modernidad de la sociedad.

Los derechos humanos en general, el derecho penal, constituyen precisamente tecnologías de la exclusión; la política igualmente produce exclusión utilizando el recurso de la alteridad, genera odio y violencia, inventa a los enemigos mediante el recurso de la tecnología de la información; de hecho ésta ha utilizado a los medios electrónicos y las fake news para producirla, es así como ella ha producido su consenso: se ha legitimado.

El futuro es cada vez más incierto. La forma en que el derecho y la política tratan de vincular el futuro se ha vuelto más problemático. Frente a los riesgos que ha producido la política (mediante los medios electrónicos y las fake news) el derecho poco puede hacer. Y también aquel ha servido como instrumento de la política para producir exclusión.

Como decíamos, la verdad, esta idea persistente de la tierra firme, en los diversos espacios comunicativos de la sociedad moderna, ha sido un problema que ha atravesado todo el pensamiento social contemporáneo. Téngase presente que la constitución de las ciencias sociales como ciencias, para adquirir ese estatus de cientificidad, esa dignidad debería tener como pretensión sujetar la objetividad, sin interferencias intersubjeti$\operatorname{vas}^{12}$ que obnubilen el acceso al conocimiento, a la aprehensión de la verdad, el deber ser en la sociedad.

Sea lo que sea esta tierra firme (= verdad), en torno a ella siempre se argumenta de modo ontológico-sustancial, ${ }^{13}$ independiente del subjetivismo, sustraídas de la temporalidad. Esto vale para la factualidad como para la metafísica. Solo que esta verdad-certeza de la sociedad moderna en realidad constituye un non-sapere ${ }^{14}$, como se ha indicado. Es en realidad una semántica vacía que rellenan, de vez en vez, los sistemas sociales. Es un artefacto, una herramienta de museo, ${ }^{15}$ que no sirve para ordenar al mundo. Que solamente tiene valía y puede mantenerse en su abstracción. Y, de este modo, la tarea más relevante de la sociedad, en efecto, es la determinación de sentido.

Nuestras expectativas, apoyadas en la inclusión universal, nos impiden observar que realmente estamos frente al riesgo, y que frente a él somos impotentes. Que, para

\footnotetext{
12 Cfr. LUHMANN, Niklas y Raffaele DE GIORGI. Teoria della società. Milano, Ed. Franco Angeli, 2008, p. 10.

13 Cfr. KAUFMANN, Arthur. La filosofía del derecho en la posmodernidad, Bogotá, Editorial Themis, 2007, p. 41.

14 DE GIORGI, Raffaele. Sin destino, escrito inédito.

15 DE GIORGI, Raffaele. Los derechos fundamentales en la sociedad moderna. Tradución del italiano Javier Espinoza de los Monteros, México, Ed. Fontamara, 2015, p. 67.
} 
decirlo metafóricamente: realmente estamos en las manos de Dios. Ellas bloquean cognición, el conocimiento del real funcionamiento de los sistemas.

Fuimos testigos y observadores de esto que estamos hablando.

Teníamos el mismo problema, los mismos mecanismos e instrumentos para combatir, hacer frente. Las constituciones, los derechos humanos, los procedimientos jurídicos, las garantías. En otras palabras, Un problema común, (la pandemia) y herramientas que nos son comunes. En efecto, aquellas piezas de museo, ocultan la forma normal de la operatividad de la sociedad moderna: la inclusión que produce simultáneamente exclusión. Estas semánticas se han podido constituir mediante la invención de la negación, del rechazo, de lo que se percibe como contrario a ellas mismas, siendo que en realidad lo que se trata como contrario, como valor negativo, como aquello que es objeto de exclusión, son ellas mismas. La negación, la otra parte de los valores son los valores mismos. Solo que para que puedan constituirse como valores necesitan negarse así mismo, la otra posibilidad, el otro sentido. Es una forma a través de la cual la razón de los valores se inmuniza frente a la exterioridad, frente a la variabilidad: autoconservación.

Y así, nos enfrentamos al problema, a los dilemas del límite, la Restricción de las libertades: y con ello una diversidad de propuestas de solución, de modos de hacer frente al problema. Nosotros sabíamos (desde la teoría de los sistemas) que, en todo caso, se trataba de hacer frente a la complejidad y de reducir complejidad, de selectividad, mediante elección del sistema. De seleccionar entre posibilidades.

Por ejemplo, han suscitado grandes controversias, precisamente por la ausencia de una orientación si:

Se debería hacer obligatorio el uso del cubrebocas por la protección de la salud de todos, o si solamente era una sugerencia para no menoscabar las libertades (como sostuvo el gobierno mexicano); en cambio para el gobierno italiano resultaba indefectible utilizarlo (obligatorio, por el bien común), se priorizaba la salud. En todo caso, en México la obligatoriedad del uso del cubrebocas se realizó de una manera azarosa, nada uniforme, en ciertas entidades y en determinados espacios.

Si se debía restringir la libertad de tránsito o solamente la libertad de reunión. En Alemania la Merkel decía que solo la libertad de reunión; por su parte en Italia se restringió la libertad de tránsito; en México, en cuanto al libre tránsito, en algunas partes si en otras no (se dejó en manos de las entidades federativas, con soluciones y medidas diferentes, incluso fuera del marco legal); 
Hasta qué punto, por la protección de la salud, podía sacrificarse la economía, limitar la libertad para trabajar (afectando a las empresas y sus trabajadores), de tránsito o de reunión;

Y derivado de lo anterior: cuál era la responsabilidad que tenían los patrones o empleadores en tiempos de pandemia frente a sus trabajadores si no hay producción e ingresos y los trabajadores no laboran, ¿se les debía pagar su salario íntegro o no?;

En caso de saturación de los servicios hospitalarios ¿cómo se tendría que proceder para la atención de los pacientes? Porque los recursos eran finitos ¿se tenía que ponderar? pero en todo caso no se podría excluir a nadie. ${ }^{16}$

Naturalmente las paradojas se resuelven siempre mediante la selectividad.

Y así, en México, los adultos mayores, con complicaciones, se dejaban al último, se jerarquizaba la atención. En caso de que existieran condiciones similares se debía de dejar a la suerte, al azar, a aventar una moneda al aire (un volado). Eran condiciones en las que no operaba ya el derecho. En Brasil acontecía algo similar. Entonces todos somos iguales pero a un mismo tiempo no, hay trato diferenciado mediante la ponderación, mediante la tutela de las expectativas como si fuera superior/inferior, mayor valía/ menor valía, igualdad/desigualdad. Otra vez se puede decir: estamos incluidos porque estamos excluidos.

Ciertamente con los principios se puede todo, solo que de manera abstracta. Pero así solamente nos encontramos en un callejón sin salida. Entonces opera la construcción del fundamento, lo variable, lo cambiante. ${ }^{17}$ De aquí que en la literatura jurídica de los Estados constitucionales, y desde una perspectiva comparada, se haya puesto de manifiesto y a discusión las distintas respuestas dentro del sistema del derecho.

Estos solamente son algunos entre otros problemas, entre otros interrogantes sobre la función de la verdad que, en todo caso, muestran la contingencia de esta verdad, que la realidad de los derechos, de los fundamentos está dentro del derecho y la política.

Era claro que el deber ser del mundo moderno no decía nada.

\footnotetext{
16 La Comisión Interamericana de Derechos Humanos recomendó, en su Resolución 1/2020 denominada "Pandemia y Derechos Humanos en las Américas”.

17 LUHMANN, Niklas. Los derechos fundamentales como institución. Aportación a la sociología política. Traducción Javier Torres Nafarrate, México, Ed. Universidad Iberoamericana, 2010, p. 64.
} 


\section{La paradoja de la información en tiempos de la Covid: fake news}

Los medios de comunicación, las fake news (que son también media), su tratamiento, la preocupación ha girado, se ha concentrado también en relación a la verdad. Que se difundiera la verdad. Que la información fuera fidedigna. Mas la verdad es siempre una construcción de realidad. Porque en efecto, nosotros somos parte del mundo que describimos, nosotros formamos parte de la realidad que construimos. Para decirlo hegelianamente, el hombre no se puede despegar de su piel. ${ }^{18}$ Somos constructores de objetos, de realidad. Esto no significa que la verdad pueda ser cualquier cosa. En relación a los medios de comunicación y su relación con la verdad la narración, el relato debe de tener plausibilidad, ser viable (como se dice estar respaldada y tener presunción de veracidad) mas, ciertamente, no es una realidad ontológica-sustancial. Esto permite distinguir entre noticia falsa y noticia verdadera. Esto quiere decir que no se puede acceder a la verdad (objetiva) pero tampoco se puede renunciar a la verdad (como construcción / plausible).

La mass media y las llamadas fakes no son otra cosa que comunicación, ellos son sociedad. Ellos producen comunicación, se activa comunicación, se expande comunicación. Los medios operan siempre al presente, permiten circular una importante cantidad de información, contienen información la cual siempre está disponible, se tiene un acceso amplio, se puede expandir constantemente. Digamos también que los medios electrónicos de comunicación nos permiten acceder fácilmente a la información. El problema es que hay una abundante información, hay una exceso de información. Estamos saturados. Ellos permiten la circulación de noticias falsas y noticias verdaderas. De este modo, se produce seguridad e inseguridad. La seguridad de la información y la seguridad de la desinformación que generan los medios.

Luego entonces qué han producido durante esta pandemia:

El discurso de odio, y la represión, pero también el aumento del riesgo de contagio, el control de la protección de la salud inadecuado, han sido un lugar común durante la pandemia; ésta ha servido para producir exclusión y una oportunidad para la proliferación de autoritarismos, una preocupación presente y que ha alarmado a la Organización de las Naciones Unidas. 
El miedo al otro, tomar al otro a distancia. Ello ha permitido justificar la exclusión, la violencia; siempre se usa el traje de la humanidad para justificar el actuar, para legitimar el mandato, ${ }^{19}$ se echa mano del discurso de los derechos (de su indeterminación, de su falta de contenido objetivo ${ }^{20}$, de su dualidad ${ }^{21}$ ) y así mismo se ha recurrido a la alteridad: a la construcción del otro como otro.

Se han inventado los enemigos, la construcción de la criminalidad, los terroristas y ahora del otro como potencial amenaza como fuente de contagio: inmigrantes irregulares; también los chinos, son los enemigos.

El no me toque, tomar distancia al otro ha sido entendido en un sentido negativo. No como respeto al otro, como amor por el otro, como responsabilidad sino para ejercer represión y violencia. No como vínculo de hermandad, de apoyo. Como escribe Slavoj Žižek:

No me toques», según Juan 20, 17, es lo que le dijo Jesús a María Magdalena cuando ella lo reconoció después de su resurrección. ¿Cómo he de entender yo, un ateo cristiano confeso, esas palabras? En primer lugar, quiero asociarlas con la respuesta de Cristo cuando sus discípulos le preguntan cómo sabrán que ha vuelto, que ha resucitado. Cristo les dice que estará allí donde haya amor entre sus creyentes. Estará allí no como una persona a la que se puede tocar, sino como el vínculo de amor y solidaridad entre la gente. De manera que «no me toques, toca y relaciónate con los demás en el espíritu del amor. ${ }^{22}$

Cada vez que Trump declara en los medios de comunicación él sabe que a través de la comunicación genera capital político, adhesión de un cierto sector de la población. Son declaraciones de discurso de odio, y esto es claro:

México envía lo peor de sus personas, no a lo mejor de sus personas, a personas con problemas que vienen a generar problemas; los delincuentes vienen a nuestro país, a cometer delitos. Y junto con los otros migrantes criminales y terroristas ponen en riesgo la seguridad de los ciudadanos, de este modo los convierte, para usar la expresión de Howard

19 Cfr. FÖGEN, Marie Theres. La canción de la ley. Madrid: Marcial Pons, 2013.

20 VILLEY, Michel. Il diritto e I diriti dell'uomo. Traducción dal francese di Liliana Botero. Siena: Edizioni Cantagalli, 2009 , p. 9.

21 SUPIOT, Alain. “La pobreza bajo el prisma del derecho", en Universitas. Revista de Filosofía, Derecho y Política, n. 20, julio 2014, p. 80 y ss.

22 ŽIŽEK, Slavoj. Pandemia. La Covid-19 estremece al mundo. Traducción Damià Alou. Barcelona: Ed. Anagrama, 2020. 
Becker, en Outsiders. ${ }^{23}$ Son declaraciones, mensajes feak; a ello se le ha añadido un pseudo-nacionalismo que reivindica la pertenencia y excluye al otro, que intenta justificar el racismo; una política del chauvinismo del bienestar en la que los otros vienen, como aves de rapiña, a aprovecharse y explotar los recursos de los nacionales, también difundida a través de su mensaje.

Todo esto en torno al color de la piel, a la religión, a la pobreza, los enemigos. Lo que ha acontecido ha sido: la represión, expansión del racismo, violencia policial, sus excesos contra la población negra, contra los migrantes.

Sobre ellos se descarga la fuerza punitiva. Un estado de seguridad. Se instrumentaliza el derecho penal contra los enemigos, contra los que representan un potencial problema contra la seguridad. ${ }^{24}$

Y en torno a ello se ha producido, como es sabido, movimientos de protesta social. Y se seguirán produciendo. Los cuales pueden ser tratados como temas para la democracia, como posibilidades, o bien reprimidos. Ciertamente esta pandemia es propicia para los movimientos de protesta contra la exclusión.

Algo que no es nuevo solo que ha alcanzado amplias dimensiones, se ha agudizado, se ha tornado más violento.

México, apelando a la pandemia, haciéndole el trabajo sucio a Trump, ha deportado a los migrantes, sin tomar ninguna medida sanitaria. El muro es México, las autoridades fronterizas. Por si fuera poco las medidas vienen justificadas con un carácter humanitario. Como si se estuviera comprometido con los derechos humanos. Los deportan para que no vayan a contagiarse. Pero en realidad los dejan varados en las fronteras, expuestos al contagio o en los centros de detención (cuyo trato ahí ha sido asimilado a tortura, sin ninguna medida sanitaria).

Los chinos, según Trump, en sus declaraciones eran los culpables de haber fabricado y difundido el virus. El enemigo. Que el virus no era natural sino una creación humana y que había sido intencional su propagación. Según el mandatario había evidencia de que el virus había sido creado en un laboratorio:

"Es algo terrible que sucedió... Ya sea si cometieron un error o si empezó como un error y luego cometieron otro, o si alguien hizo algo a propósito”, ${ }^{25}$

23 Cfr. BECKER, Howard, Outsiders. Hacia una sociología de la desviación, Buenos Aires, siglo XXI Editores, 2009.

24 Sobre esto puede verse: WACQUANT, Löic. "La penalización de la miseria. De la importación de políticas de seguridad”, en A renglón seguido, mayo-agosto de 2002, p. 6.

25 “Trump considera que China liberó el coronavirus por error", Milenio, 30/04/2020, disponible en https://www. milenio.com/internacional/estados-unidos/donald-trump-cree-china-libero-coronavirus-error. 
En realidad es una actitud criminal, que genera odio, exclusión, violencia. Y de nueva aquí emerge la paradoja de los principios porque Trump hacía sus declaraciones en uso de la libertad. Pero también se puede decir que ello atenta contra la seguridad de las personas. Es, como se ha dicho, criminal. Y ha generado consecuencias terribles. Lo mismo se puede decir de la política de Bolsonaro que, como en toda democracia autoritaria, se apoya en el nombre del pueblo. Un escudo legitimador que inmuniza a la política contra el soberano.

Este es el poder de los medios, su instrumentalización, uno entre otros usos por parte de la política.

También piénsese en las noticias que han circulado y difundido los medios, en las cuales escuchamos la perversidad de las democracias autoritarias y de los populismos durante esta pandemia, sobre las medidas sanitarias. Los ejecutivos de varios países, de estas democracias autoritarias, han dado poca importancia a la pandemia $Y$ en esas condiciones cómo podía tomarse en serio la población la situación de gravedad. De hecho, eran actuaciones, grotescas, caricaturescas, indignantes, pero también eran, por decirlo así criminales, inmorales:

El mandatario mexicano decía que la "honestidad" era el mejor "escudo protector” y, sin ningún empacho, invitaba a salir, se decía: "no pasa nada”; en Brasil, Jair Bolsonaro decía que se trataba de un simple resfriadinho. Incluso consecuente con su poca preocupación en torno a la pandemia, ha declarado que han sido mejor las medidas laxas ya que sería peor morirse de hambre; él hace “... lo que el pueblo quiera”. ${ }^{6}$ Como es sabido se han dado declaraciones y medidas que dejan a cualquiera desconcertado, y que generan confusión y polémica. Ha sido una actitud negligente y arbitraria pero según aquel estas medidas es lo que habría impedido "la inminencia de tener problemas (sociales) serios”, que generan fuertes medidas restrictivas.

Para Donald Trump, en Estados Unidos de Norteamérica, no había de que preocuparse ya que la situación estaba bajo control; Según las consideraciones del mandatario de Bielorrusia, en una pista de hielo estaba la cura de la Covid. Estas expresiones, estas actitudes, estos exhortos tienen en común un carácter gravísimo, criminal, contribuyen a la difusión del virus y con ello de muertes y enfermos, de saturación del servicio

26 "Brasil está en el límite; Bolsonaro lanza amenaza, en medio de investigación por su gestión de la pandemia”, en El Universal, disponible en: https://www.eluniversal.com.mx/mundo/covid-brasil-esta-en-el-limite-bolsonaro-lanza-amenaza-en-medio-de-investigacion. 
de salud. Así no se puede hacer frente a un control, no se puede evitar la propagación. La desinformación le resta gravedad a la situación, pero la despreocupación ha conducido a las peores consecuencias.

Para López Obrador todo estaba perfectamente controlado, se contaba con todos los instrumentos y equipo médico, con la infraestructura necesaria. Garantizaba, no había de que preocuparse. El resultado es que México es el cuarto país con más muertes, se pelea por el tercero y cuarto lugar. Y Estados Unidos de Norteamérica ha sido el campeón.

Luego tenemos las fake news que circulan en las redes sociales. Ellas son también comunicación. No son buenas ni malas. El problema es el uso de la política y de ciertos grupos de intereses criminales, comerciales, etc. Hemos visto circular todo este tiempo, durante la pandemia, una cantidad casi infinita, inagotable de mensajes los cuales han:

-Generado pánico, alarma y angustia entre la población; instaban a que se adquiera, a consumir algunos productos y medicamentos. Se trataba de información sensacionalista, que producía el desabasto, compras innecesarias y provocaba que las personas quedaran expuestas, pues saturaban los negocios. También se encontraba el otro extremo, por ejemplo, sugerían que no existía el virus, que era un invento de los gobiernos, o bien que en lugares cálidos no había riesgo de transmisión. Todo ello ha repercutido en la salud mental y física. Además, ha producido ansiedad entre las personas.

La desinformación, por tanto, ha aumentado el riesgo de contagio, se ha expuesto a las personas con supuestas soluciones médicas (supuestas curas o medicamentos para tratar la enfermedad). Empero, ni siquiera la ciencia tenía una respuesta satisfactoria hasta ahora.

Las noticas han proliferado y, de este modo, han constituido una fuente de ganancias por las visitas en redes sociales, por difusión de la información. Falsa o verdadera ella se deja, permanece porque es rentable.

-En materia política se ha producido una polarización en el debate público. Al no contarse con una información fidedigna, la crítica es manipulada.

En todo caso:

La ausencia de una explicación, unida a la imperiosa necesidad de encontrar una que sea satisfactoria, hacen de las crisis, por tanto, el momento ideal para que proliferen las noticias falsas. Se compite por dar una explicación, por construir el relato que triunfe, elaborar el signo que 
permita en tender lo sucedido y facilite la vida futura. Es mucho lo que se está jugando aquí: la identificación del culpable y la interpretación que habrá que dar a la realidad en adelante. ${ }^{27}$

Es por ello que las fakes news han sido consideradas como la otra pandemia: la así llamada infodemia. ${ }^{28}$ Por la facilidad y rapidez con la que se propagan, y por el impacto que pueden generar. Incluso todo parece indicar que esta vicisitud del proceso de recepción de información incorrecta tiene igual o, tal vez, mayor gravedad que el propio virus que nos aqueja, ello: “al tener la capacidad de poner en riesgo la salud e integridad de las personas." 29 En todo caso: "la infodemia potencia el impacto de la pandemia."30

La apelación a la responsabilidad moral, no difundir información sin previa verificación, tener la capacidad de discernir, ${ }^{31}$ cierto que abona pero no las frena; estas siguen multiplicándose. Esto no quiere decir que no se encaminen esfuerzos para la prevención, ${ }^{32}$ lo que se quiere decir es que esto no ha resultado suficiente, que sigue propagándose de forma, precisamente, viral. Con una gran complejidad para su erradicación. Cierto que es peor no hacer nada. Así como es cierto que el problema persiste y se potencializa.

No solamente se ha propagado el virus de la enfermedad sino también el virus de la desinformación y con ello el virus del odio, de la exclusión.

El derecho solamente puede intervenir después, cuando ya se han producido las consecuencias. En este sentido, la prohibición no impide, no asegura que se continúen

27 LOSADA MAESTRE, Roberto. “Las Fake News en la crisis de la Sociedad digital”, en Más Poder Local, n. 41, abril 2020, p. 49.

28 "Una infodemia es una sobreabundancia de información, en línea o en otros formatos, e incluye los intentos deliberados por difundir información errónea para socavar la respuesta de salud pública y promover otros intereses de determinados grupos o personas.", en “Gestión de la infodemia sobre la Covid-19: Promover comportamientos saludables y mitigar los daños derivados de la información incorrecta y falsa”, Declaración conjunta de la OMS, las Naciones Unidas, el Unicef, el Pnud, la Unesco, Onusida, la UIT, la iniciativa Pulso Mundial de las Naciones Unidas y la Federación Internacional Sociedades de la Cruz Roja y de la Media Luna Roja, Organización Mundial de la Salud, 23 de septiembre de 2020, disponible en: https://www.who.int/es/news/item/23-09-2020-managing-the-covid-19-infodemic-promoting-healthy-behaviours-and-mitigating-the-harm-from-misinformation-and-disinformation.

29 MENDOZA, Miguel Ángel. "Fake news y sus riesgos en tiempos de covid”, en: https://www.welivesecurity.com/ la-es/2020/07/02/fake-news-riesgos-covid-19/

30 MENDOZA, Miguel Ángel. Op cit.

31 “... actuar de manera responsable consiste en analizar el impacto que podría tener la difusión de la información, dedicar tiempo para conocer el contexto de la nota (fuente, fecha, medio), así como salir de la burbuja y consultar más al respecto antes de compartir.” MENDOZA, Miguel Ángel. Op. cit.

32 "Dado el impacto y el riesgo de este fenómeno, algunas plataformas sociales, como Facebook, Google, LinkedIn, Microsoft, Twitter, Reddit y YouTube se unieron en el combate de la desinformación y las estafas que giran en torno a la pandemia, cambiando las reglas para censurar como en el caso de Twitter aquellos mensajes que incitaban a las personas a actuar en contra de las recomendaciones oficiales.” Op cit. 
produciendo, las conductas acontecen para decirlo weberianamente, solo posteriormente viene el derecho. No sabemos incluso si apelar a su prohibición aumentaría el deseo de trasgresión. Es una alternativa, un riesgo que puede tomarse.

Queda la paradoja, porque:

La enfermedad por coronavirus (COVID-19) es la primera pandemia de la historia en la que se emplean a gran escala la tecnología y las redes sociales para ayudar a las personas a mantenerse seguras, informadas, productivas y conectadas. Al mismo tiempo, la tecnología de la que dependemos para mantenernos conectados e informados permite y amplifica una infodemia que sigue minando la respuesta mundial y comprometiendo las medidas para controlar la pandemia. $^{33}$

Queda el hecho de que: “cada paso adelante acarrea un aumento de angustia”. ${ }^{34}$ Otra paradoja: entre más saber más no saber.

Nosotros no sabemos si estos valores, si nuestros fundamentos, si nuestra idea de progreso, han llegado a su fin. Podemos decir que ahora podemos ver, con esta pandemia su realidad, su fragilidad, precisamente su incertidumbre. Puede ser que ante esta oscuridad sobrevuele nuevamente el búho de minerva, alce el vuelo en la oscuridad, esto es, que se produzcan por el pensamiento otros valores que sustituyan a estos, que puedan ordenar al mundo. Lo que se puede decir es que ellos han sido valores de su tiempo. Los nuevos fundamentos en realidad pintarían gris sobre gris, como decía Hegel. Porque en esta sociedad estamos sin destino, como dice mi querido maestro, Raffaele De Giorgi. Se producirá seguramente la reconciliación, esto es, la continuidad de los valores, en otra forma, presentados en otra semántica, pero seguirán teniendo la misma función, ocultar las observaciones, el rechazo de la complejidad social. A contracorriente, el pensamiento sociológico-sistémico es una alternativa que muestra lo sagrado como variable, no es una irreverencia, sino como decía Luhmann, otra forma de pensar. $^{35}$

\footnotetext{
33 "Gestión de la infodemia sobre la Covid-19: promover comportamientos saludables y mitigar los daños derivados de la información incorrecta y falsa”. Op cit.

34 Cfr. BURY, John. La idea de progreso. Traducción Elías Díaz García, Madrid, Ed. Alianza, 2009, pp. 338-339.

35 LUHMANN, Niklas. Los derechos fundamentales como institución. Aportación a la sociología política. Traducción Javier Torres Nafarrate, México, Ed. Universidad Iberoamericana, 2010, p. 64.
} 


\section{FUENTES DE INFORMACIÓN}

BURY, J. La idea de progreso. Traducción Elías Díaz García. Madrid: Ed. Alianza, 2009.

DE GIORGI, R. Observación sociológica de la filosofía del derecho. Traducción Javier Espinoza delos Monteros. México: Ed. Derecho Global, 2018.

DE GIORGI, R. Los derechos fundamentales en la sociedad moderna. Traducción Javier Espinoza de los Monteros. México: Ed. Fontamara, 2015.

DE GIORGI, R. Sin destino, escrito inédito.

EL PAÍS. Pensadores ante la crisis. 17 mayo 2021. YouTube: El País. Disponible en: https://www.youtube.com/watch?v=C9tw09IzQdM. Acceso en: 4 ago. 2021.

EL UNIVERSAL. "Brasil está en el límite”; Bolsonaro lanza amenaza, en medio de investigación por su gestión de la pandemia. 14 abr. 2021. El Universal. Disponible en: https://www.eluniversal.com.mx/ mundo/covid-brasil-esta-en-el-limite-bolsonaro-lanza-amenaza-en-medio-de-investigacion. Acceso en: 4 ago. 2021.

ESTÉVEZABAD, R.F. “¿Pandemia o pandemias?”. Revista internacional de pensamiento político, Iépoca, v. 15, p. 167-186, 2020.

FÖGEN, M. T. La canción de la ley. Madrid: Marcial Pons, 2013.

ISLAS COLÍN, A. “Derechos humanos en México antes el coronavirus”. Actualidad Jurídica Iberoamericana, n. 12 bis, p. 52-61, mayo 2020.

KAUFMANN, A. La filosofía del derecho en la posmodernidad. Bogotá: Editorial Themis, 2007.

LOSADA MAESTRE, R. “Las Fake News en la crisis de la Sociedad digital”. Más Poder Local, n. 41, abr. 2020.

LUHMANN, N. ¿Cómo es posible el orden social? Traducción Pedro Morandé Court. México: Herder / Universidad Iberoamericana, 2009.

LUHMANN, N. Los derechos fundamentales como institución. Aportación a la sociología política. Traducción Javier Torres Nafarrate. México: Ed. Universidad Iberoamericana, 2010.

LUHMANN, N. Ilustración sociológica y otros ensayos. Traducción H. A. Murena. Buenos Aires: Ed. SUR, 1973.

LUHMANN, N. La observación sociológica del derecho. Traducción Héctor Fix-Fierro. Crítica jurídica. Revista latinoamericana de Política, Filosofía y Derecho, n. 12, Universidad Nacional Autónoma de México-Instituto de Investigaciones Jurídicas, México, 1993.

LUHMANN, N.; DE GIORGI, R. Teoria della società. Milano: Ed. Franco Angeli, 2008.

ORGANIZACIÓN MUNDIAL DE LA SALUD. Gestión de la infodemia sobre la Covid-19: promover comportamientos saludables y mitigar los daños derivados de la información incorrecta y falsa. 23 sept. 2020. Disponible en: https://www.who.int/es/news/item/23-09-2020-managing-the-covid-19-infodemic-promoting-healthy-behaviours-and-mitigating-the-harm-from-misinformation-and-disinformation. Acceso en: 4 ago. 2021. 
SUPIOT, A. “La pobreza bajo el prisma del derecho”. Universitas. Revista de Filosofía, Derecho y Política, n. 20, p. 78-87, jul. 2014.

TRUMP considera que China liberó el coronavirus por error. Milenio, Washington, 30 abr. 2020. Disponible en: https://www.milenio.com/internacional/estados-unidos/donald-trump-cree-china-libero-coronavirus-error. Acceso en: 4 ago. 2021.

VILLEY, M. Il diritto e i diriti dell'uomo. Traducción Liliana Botero. Siena: Edizioni Cantagalli, 2009.

WACQUANT, L. La penalización de la miseria. De la importación de políticas de seguridad. A renglón seguido, mayo/ago. 2002.

WELIVESECURITY. Fake news y sus riesgos en tiempos de Covid-19. 2 jul. 2020. https://www.welivesecurity.com/la-es/2020/07/02/fake-news-riesgos-covid-19/. Acceso en: 4 ago. 2021.

ŽIŽEK, S. Pandemia. La Covid-19 estremece al mundo. Traducción Damià Alou. Barcelona: Ed. Anagrama, 2020. 